\title{
TEMPO - UMA CATEGORIA, VÁRIAS ABORDAGENS
}

Julieta Beatriz Ramos Desaulniers*

SÍNTESE - O presente artigo aborda o tempo enquanto uma categoria de análise, de interesse universal, com possibilidades de oferecer uma compreensão globalizante dos fenômenos, já que integra a realidade como um todo. Assim, as várias áreas da ciência têm condições de articularse através de estudos e pesquisas que privilegiam o tempo, pois é uma categoria que se constrói na multiplicidade e, por isso, expressa/condensa as inúmeras dimensões que compõem o real.

\begin{abstract}
The present article approaches time while analysis category of universal interest with possibilities of offering a globalizing understanding of phenomena, since it integrates reality as a whole. Thus, the different areas of science have conditions of getting articulated through studies and research that focusses. on time, for it is a category that is built within multiplicity and therefore expresses/condenses the countless dimensions that constitute reality.
\end{abstract}

Pretendo tecer comentários sobre os principais termos que refiro no título, com o intuito de salientar o significado do tempo na construção do social.

Qual foi a primeira reação ao lerem o título desse curso? Pareceu-lhes, num primeiro momento, que se tratava de algo tão óbvio - $O$ tempo - que, possivelmente, não fazia muito sentido organizar todo um curso sobre isso, não é mesmo? Talvez, em parte, vocês estavam com razão, caso tenham pensado assim. Por que?

O vínculo que cada um de nós tem com o tempo é tão antigo que remonta não só aos primórdios da nossa própria história individual, mas aos primórdios da história de toda humanidade . Em função disso, a ligação que temos com o tempo é tão estreita, tão íntima e, portanto, repleta de cumplicidades, que isso pode dificultar e mesmo impedir a objetivação da teia complexa de relações que constitue um dado fenômeno, em que o tempo é um dos seus principais elementos.

Ou seja, a nossa interação com essa realidade é praticamente desapercerbida porque o tempo faz parte de nós, quase como o ar que respiramos, visto que somos constituidos no e com o tempo, ao ponto de não existirmos sem ou fora do tempo, assim como o tempo não existe senão em nós enquanto a sua expressão, a sua materialidade.

- Pontifícia Universidade Católica do Rio Grande do Sul, PUCRS.

\begin{tabular}{|l|l|l|l|l|l|}
\hline VERTTAS & Porto Alegre & v. 41 & $\mathrm{n}^{\circ}$ 162 & Junho 1996 & p. 315-321 \\
\hline
\end{tabular}


Sobre isso, Grimaldi, ao proferir uma palestra ${ }^{1}$ na Sorbonne/Paris, em março de 1993, para a Sociedade Francesa de Filosofia, lançou a seguinte indagação: a vida não é por excelência o fenômeno do tempo? Ele mesmo responde dizendo que essa é uma questão indiscutível, tanto que nada do que existe é intemporal.

Por outro lado, existe um certo consenso entre os que investigam essa temática no sentido de que "o tempo é um conceito que não admite nenhuma definição". ${ }^{2}$ Para o próprio Santo Agostinho, um dos grandes interessados no assunto, a medida do tempo é realizada pela alma e pelas impressões que ela possui nela própria, parecendo-lhe assim bastante misterioso esse fenômeno.

O fato de vivermos o tempo no nosso dia-a-dia, através das inúmeras formas que o constituem, faz com que tenhamos uma relação de intimidade com o tempo, mesmo se não somos capazes de defini-lo precisamente. Prova disso é que qualquer pessoa para se reconhecer enquanto tal face a ela própria e às demais, recorre/reune alguns momentos dos tempos vividos e/ou pensados que marcaram a sua existência, resultando dai a consciência que ela tem da sua trajetória/da sua história.

Partindo-se dessas considerações, constata-se também, conforme Gaston Bachelard ${ }^{3}$ e outros, que o tempo é constituido de um conjunto de instantes. O tempo é determinado, é sempre de um certo tempo "que se fala". Por isso, não se pode falar de um conceito de tempo, mas de concepções de tempo.

Nesse sentido, vários momentos podem ser citados como exemplos da multiplicidade de dimensões em que a nossa vida está relacionada/ritmada/construída com e pelo tempo:

$\begin{array}{lll}\text { o tempo do trabalho } & \text { o tempo da escola } & \text { o tempo do imaginário } \\ \text { o tempo do lazer } & \text { o tempo do hospital } & \text { o tempo da intimidade } \\ \text { o tempo meditativo } & \text { o tempo do prazer } & \text { o tempo da tristeza } \\ \text { o tempo da alegria } & \text { o tempo da dor } & \text { o tempo da espera } \\ \text { o tempo mecânico } & \text { o tempo criativo } & \text { o tempo de criança } \\ \text { o tempo de adulto } & \text { o tempo do pobre } & \text { o tempo do pobre }\end{array}$

Além do tempo não ser visível e apreensivel, mesmo se é divisível, conforme vimos anteriormente, o tempo é também descrito como a melhor e a pior das coisas. Isso está associado aos inúmeros momentos da história que tem marcado profundamente a consciência relativa ao tempo", 4 os quais estão expressos em vários ditados populares. Atualmente, é muito comum ouvir dizeres como:

$\begin{array}{lll}\text { o tempo voa } & \text { o tempo não pára } & \text { o tempo não espera } \\ \text { o tempo apaga tudo } & \text { o tempo corre } & \text { o tempo ilude } \\ \text { correr para ganhar tempo } & \text { tempo é dinheiro (gasta-se) } & \text { tempo é liberdade } \\ \text { tempo é poder } & \text { tempo é felicidade } & \text { tempo se conquista } \\ \text { tempo é prazer } & \text { tempo é esquecimento } & \text { o tempo engendra } \\ \text { o tempo inova } & \text { o tempo apaga } & \text { o tempo arruina }\end{array}$

1 GRIMALDI, Nicolas. "Le temps peut-il être un principe?" In: Bolletin de la Société Française de Philosophie. Paris: Armand Colin, t. LXXXVII, 1993.

2 CIORANESCU, A. "La forme du temps. In: Revue Diogène. Paris: UNESCO, n. 149, 1990.

3 BACHELARD, Gaston. A dialética da duração. São Paulo: Atica, 1988.

4 BERTHELOT, Jean-Michel. 1991, p. 104. 
Essas inúmeras expressões referentes à vivência do tempo, constituem o homem na sua relação dialética com o real. Essa relação é construída num determinado tempo e espaço, com base no pensado e no vivido e está articulada aos sitemas simbólicos variados que configuram/definem/integram a dinânica e a complexidade de um determinado contexto social.

Em outros termos, sendo o tempo a própria realidade, "ele é material, ele é quem faz com que a matéria (o real) não acabe nunca de se transformar, de mudar e de produzir nela (na matéria - no real) uma infinitude de modos diferentes de temporalidades" ${ }^{5}$

A questão que se coloca é a seguinte: "Temporalidades diversas são feitas para se encontrarem ou permanecerem isoladas. Caso sejam feitas para se encontrarem, temos então que organizar uma maneira de reunir essa dispersão de tempos diversos". ${ }^{\prime}$

Nós, enquanto indivíduos, articulamos todos os inúmeros tempos que nos constroem, em função das nossas condições pessoais e sociais, que vão desde os níveis de instrução e de cultura associados ao status sócio-econômico, até o nosso grau de equilíbrio emocional. Assim, configura-se a percepção e, conseqüentemente, o modo pelo qual uma dada sociedade materializa-se/constrói-se com e no tempo.

No entanto, para se capturar o sentido das temporalidades dirpersas experimentadas pelos indivíduos que integram uma dada sociedade e, assim, instaurar uma ruptura/uma superação do senso comum sobre a sua dinâmica, é necessário uma abordagem baseada em procedimentos científicos. Aliás, esse é o papel do cientista: dizer/captar o que o senso comum é incapaz de perceber. ${ }^{7}$ Essa é uma questão que pretendo desenvolver na exposição sobre "tempo e construção do social".

No momento, vale assinalar que o tempo é uma categoria que se constitui efetivamente numa categoria de análise de caráter universal, pelo seu significado junto à construção do social, conforme considerações bem gerais que apresentei anteriormente.

\section{O que é uma categoria de análise?}

De acordo com Émile Durkheim, atribuir a um termo a condição de categoria significa compará-la a uma ferramenta, aqui entendida enquanto capital material acumulado, entendendo que ambas - categoria e ferramenta - têm um parentesco com instituição social. ${ }^{8}$ Nesse sentido, afirma que a categoria tempo exprime o tempo comum a um grupo e, por isso, "ela própria (a categoria tempo) é verdadeira instituição social".

5 GRIMALDI, op. cit., p. 109.

6 MARRE, Jacques Léon. "Histónia de vida e método biográfico". In: Cademos de Sociologia. Porto Alegre: UFRGS, v. 3, n. 3, 1991.

7 BOURDIEU, Pierre. O poder simbólico. Lisboa: Difel, 1989, p. 53.

8 DURKHEIM, Émile. As formas elementares de vida religiosa. São Paulo: Paulinas, 1989, p. 49.

9 Idem, p. 39. 
Nessa mesma perspectiva, para Nisbet, as categorias são testemunhas que, em geral, se fazem melhor compreender que os documentos; elas contém múltiplas implicações e são associadas a coisas compartilhadas que precisam ser descobertas. $^{10}$

Ainda conforme Durkheim, uma categoria envolve tamanha complexidade, que análises tão simplistas como aquelas com que o empiricismo se contenta não são capazes de explicá-las. Para ele, as categorias aparecem como instrumentos científicos de pensamento, que os grupos humanos forjam laboriosamente no decorrer dos séculos, e onde acumularam o melhor do seu capital intelectual. Toda uma parte da história da humanidade aí está como que resumida. ${ }^{11}$

Além de Durkheim, outros estudiosos também insistem que para compreender uma categoria de análise é necessário recorrer a procedimentos diferentes daqueles que se baseiam no senso comum. Para sabermos do que são constituídas, já que não foram forjadas por nós, não é suficiente interrogarmos a nossa consciência; é para fora de nós que devemos olhar, é a história (a realidade) que devemos observar, é toda uma ciência complexa que só pode avançar lentamente, por meio de um trabalho coletivo. ${ }^{12}$

Com base nessas considerações, parecem ficar mais claros os motivos que instigaram a organizar esse curso: "O tempo - uma categoria, várias abordagens". Em outros termos, a relação que mantemos com o tempo, por estar repleta de tanta intimidade, tende a dificultar os empreendimentos em que pretendemos atingir a sua respectiva objetivação. Nessa medida, é compreensível que, ao leram o título desse curso, não tenham captado imediatamente o seu sentido e, por certo, alguns dos motivos já foram destacados aqui.

Ainda nessa mesma perspectiva, outros elementos reforçam a necessidade de se realizar cursos sobre temáticas que têm essa preocupação. Por que?

Porque o tempo não é apenas um termo em si, mas um termo que contém/condensa parte da história da humanidade e, por isso, constitui um documento, uma instituição, um verdadeiro instrumento de análise do real.

Desconhecer esse fato, desconhecer a complexidade dos significados do tempo na constituição do real, seja enquanto cidadão seja enquanto cientista, implica, obviamente, em ações e posturas que tendem a comprometer a dinâmica do próprio real.

Aliás, a nossa sociedade brasileira tem vários entraves ao seu avanço e desenvolvimento, como é do conhecimento de todos nós. Dentre eles, certas concepções e valores têm desempenhado o papel de verdadeiros obstáculos epistemológicos. Um caso exemplar, nesse sentido, refere-se à categoria tempo, que comumente aparece dissociado do real, mesmo se tudo é tempo, tudo contém um dado tempo. Ao dissociar-se o tempo da matéria (do real) nega-se o seu movimento, a mudança enquanto uma dimensão fundamental que envolve essa categoria, porque se atribui o movimento ao tempo e a conservação à matéria.

10 NISBET, R. A. La tradition sociologique. Paris: PUF, 1984.

11 DURKHETM, op. cit., p. 49.

12 Idem, p. 49. 
Vários são os dizeres populares que se referem a dimensões do tempo, alguns já citados aqui, que têm sido ratificados pela pseudo-ciência por serem apreendidos com base e a partir do senso comum. Desse modo, assumem o status de postulados científicos transformando-se em obstáculos epistemológicos ainda mais resistentes. Isso porque é sempre mais difícil romper com um conhecimento dito científico, já que ele se apresenta "com uma moral disfarçada em ciência". ${ }^{13}$

Algumas expressões denotam claramente esse problema levantado acima, em que se concebe o tempo dissociado da construção do social: "o tempo muda e as coisas continuam sempre as mesmas"; "Os governantes mudaram, mas a situação continua igual"; "gosto dos meus filhos do mesmo modo"; "fui o mesmo tipo de trabalhador a minha vida toda"; "o tempo muda e você continua sempre do mesmo jeito".

Vale lembrar que o que permanece e o que dura no tempo é apenas e tão somente aquilo que tem razões para recomeçar. ${ }^{14}$ No entanto, é muito freqüente dada a concepção de tempo que se apresenta bastante cindida do real nas várias esferas da nossa vida - a manutenção de relações (profissionais, amorosas, de amizade...) que servem quase que exclusivalmente para bloquear o movimento, a mudança, o crescimento, o desenvolvimento, a transformação enfim, já que não possuem mais aquelas condições necessárias para o recomeçar. Assim, pelas nossas ações contidas/cindidas vamos, com muita freqüência, retendo o movimento do real, visto que se está partindo do pressuposto de que o tempo muda independente da matéria, independente de nós.

Também, constitui-se obstáculo epistemológico o fato de nossa cultura ter dificuldades em compatibilizar os tempos vividos socialmente, com os de outras culturas, acentuando ainda mais as nossas defasagens frente a uma realidade de globalização da economia que supõe, ou melhor, que impõe um ritmo relativamente sincronizado entre os habitantes desse planeta.

Essa dificuldade de se organizar num tempo socialmente determinado, instaura vários problemas, dentre eles o desperdício em todos os sentidos. Quanto a isso, é suficiente lembrar a postura do brasileiro face à pontualidade e as repercussões disso na construção da realidade social.

Enfim, falar em avanço social, em ética, em liberdade, em cidadania implica, necessariamente, a instauração de certas rupturas na concepção da categoria tempo, visto que ela faz parte da nossa construção e, por isso, é um elemento constitutivo do real. Ou seja, o tempo é relação, é invenção, é construção; o tempo expressa uma estrutura sócio-cultural e porque já foi estruturado socialmente, atua enquanto estrutura estruturante do real.

Então, sem provocar rupturas em tais concepções sobre tempo, estratégias e ações teoricamente voltadas à mudança podem estar apenas reforçando os obstáculos epistemológicos mencionados anteriormente. Ou seja, ao invés de tais intervenções estimularem o movimento, tendem a criar mais resistências à mudança, visto que as suas premissas baseam-se numa visão fragmentada do real.

13 BOURDIEU. Pierre. Coisas ditas. São Paulo: Brasiliense, 1990.

14 BACHELARD, op. cit., 1988. 
Destaco ainda que, para alguns autores, são duas as principais interpretações sobre o tempo: as que se baseam em hipóteses objetivistas - relações temporais, ligadas ao conceito de movimento e que se referem às posições dos eventos no espaço; aqui, incluem-se as reflexões de pensadores como Platão, Aristóteles, Newton, Kant, Eistein; e as que se baseam em hipóteses subjetivistas - em que o tempo é a mudança, vivida continuamente pela consciência em sua relação a si e ao mundo. Os seus principais representantes são: Plotino, Santo Agostinho, Bergson, Gaston Bachelard, Levinas.

Por tudo o que se enfatizou até aqui, o tempo é uma categoria de interesse universal, não se constituindo exclusividade de nenhuma área da ciência. Pelo contrário, é essencial à constituição de cada uma delas, sendo enfocada a partir das suas perspectivas e peculiaridades.

Por isso, a inclusão do tempo nos estudos e pesquisas enquanto uma categoria de análise permite uma compreensão mais globalizante sobre a construção do social, visto que ela compõe a realidade como um todo, tendo a condição de articular as várias áreas da ciência.

$\mathrm{E}$, nessa medida, é urgente debater as várias abordagens que refletem e analisam essa temática há séculos, em especial os estudos mais recentes junto às diversas áreas do conhecimento, que vêm produzindo rupturas importantes relativas a tais concepções. Assim, desenvolver pesquisas que visam captar a complexidade que envolve a categoria tempo significa ampliar espaços propícios ao avanço da ciência, que depende em muito desse tipo de instrumental.

Esse curso privilegiou algumas áreas do conhecimento, com o intuito de se refletir mais aprofundadamente em algumas questões que venham reforçar e, assim, oferecer maior rigor científico às investigações desenvolvidas pelas Ciências Humanas e Sociais. As várias palestras do curso foram organizadas com base numa perspectiva interdisciplinar, as quais se referem a aspectos e/ou questões, tais como:

** considerações sobre o avanço da tecnologia, que tem comprimido o tempo e o espaço de forma jamais experimentada até o momento, bem como sobre a construção desse fenômeno em termos históricos;

** o tempo seria um movimento contínuo por meio do qual o presente torna-se passado? ou é um meio transcendental que coloca ordem nas relações entre os sentidos e as imagens, não sendo um simétrico do espaço, mas englobando o espaço, assim como o espaço engloba os objetos? Sendo assim, o tempo passado só pode ser captado através do espaço. Ou seja, o espaço contém o tempo comprimido e, por isso, o registro do tempo tem que ser considerado no plural e não no singular. Então, capta-se $o$ tempo passado pelas memórias - as " $n$ " possibilidades de materialização do social?

** Em que consiste o tempo interno do indivíduo? Quais as implicações junto à construção individual e, conseqüentemente, junto ao social o fato de o indivíduo ter dificuldades em "lidar" com o seu tempo, quando tem muito pouca consciência do seu próprio ritmo pessoal? Esse tipo de indivíduo está perdido na dispersão? Que repercussões isso traz à dinâmica do social?

** Em que medida a narrativa literária constitui um registro do tempo?

** Existe, afinal, algum espaço de liberdade ao homem na construção do social, face ao papel estruturante do tempo? Quais são os pressupostos para a reali- 
zação da liberdade? Como a contingêncịa constitui um elemento/uma possibilidade para se concretizar a liberdade humana?

** E o tempo físico? Ele é preciso, exato, independente da percepção dos individuos? Ou o tempo é relativizado por vários fatores, os quais são demonstráveis através do próprio real? Que decorrências uma ou outra situação produz à construção do social?

** Será que fazem sentido todas essas perguntas se o tempo é uma pura espera? O tempo, afinal, não será uma simples aparência? Ou ele contém uma essência? Ou, ainda, ele é um princípio? É possível falar do ser do tempo? E, em que se constitui esse ser? Pode-se falar, também, do não ser do tempo? E o ter do tempo, em que consiste? O tempo como ser é um "fato" que ainda não encontrou a sua legitimação teórica e somente como "aparecer" é que ele, não só é teoricamente justificável, como praticamente utilizável, operacional?

Certamente, várias dessas questões que acabo de levantar, além de tantas outras, serão objeto da exposição dos nossos palestrantes. 